\title{
Disseminated tuberculosis following BCG vaccination
}

\section{KRCP Kekulawala ${ }^{1}$, BJC Perera ${ }^{2}$, J Senevirathna ${ }^{3}$ and CS Perera ${ }^{4}$}

(Index words: Caseation, dactylitis, granulomata)

\section{Introduction}

Disseminated tuberculosis is rare in infants. The more common presentations of tuberculosis (TB) in infancy include pulmonary and meningeal involvement. Disseminated TB following BCG vaccination is even rarer. The possible reasons for dissemination following BCG are faulty techniques of intra-dermal administration and use of excess doses of the vaccine. Dissemination following BCG also occurs in the setting of immunodeficiency.

\section{Case history}

A ten-week old baby boy was admitted to Lady Ridgeway Hospital, Colombo, with a history of high fever for 25 days, cough for two weeks and poor feeding. Examination revealed an ill baby with a number of erythematous plaques over the face, BCG site (Figure 1), right areola and the left thigh. There was also a swelling over the dorsum of the right foot without any overlying skin changes. He had received BCG vaccination two days after birth.

The chest xray taken on admission showed nonspecific inflammatory changes and the child was treated with conventional intravenous antibiotics. In spite of treatment he continued to have fever and diffuse changes on repeated chest films. Xray of the right hand showed radiological evidence of dactylitis. Xray of the right foot showed distorted first metatarsal. The ESR was $128 \mathrm{~mm}$ and the haemoglobin was $7.8 \mathrm{gm} / \mathrm{dl}$. The Mantoux test was negative. Bone marrow aspiration showed no granulomata and polymerase chain reaction for TB was negative. Cerebro-spinal fluid report showed no cells and was negative for acid fast acilli.

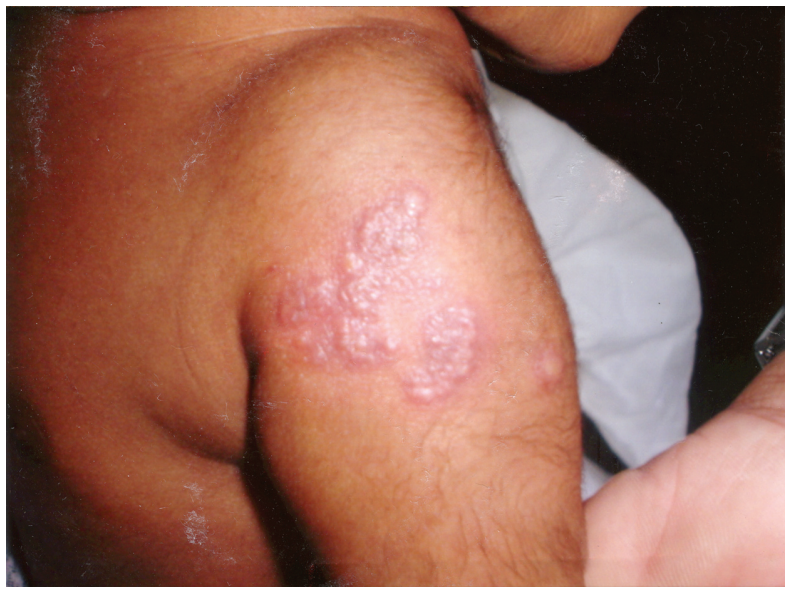

Figure 1. Erythematous plaques over BCG site.

Examination of blood for HIV and VDRL were negative. Serum immunoglobulins complement levels, CD4 and CD8 cell counts were all within the normal range. Skin biopsy was obtained from the left upper arm and this showed multiple granulomata with central caseation. The baby was then started on anti-TB therapy with rifampacin, isoniazid and pyrazinamide.

\section{Discussion}

In this baby there was overwhelming evidence to suggest a diagnosis of disseminated TB. The fact that the baby developed the illness at 6 weeks of age, lack of a positive contact history, the presence of erythematous plaques on the BCG site, and absence of evidence of immunodeficiency all favour the diagnosis of disseminated TB following BCG vaccination. Further proof of this was obtained on histological examination of the

${ }^{1}$ Senior Registrar in Paediatrics, ${ }^{2}$ Paediatrician, ${ }^{3}$ Dermatologist, and ${ }^{4}$ Pathologist, Lady Ridgeway Hospital for Children, Colombo 8, Sri Lanka.

Correspondence: KRCPK, Tel: + 9411 5353609, e-mail: <drvishchan@yahoo.com> (Competing interests: none declared). Received 13 September 2005 and accepted subject to minor amendments 18 December 2005. 
skin lesion which showed typical changes of TB. He was on triple anti-TB treatment and had completed two months of effective treatment with excellent results at the time of writing.

Though BCG has a low incidence of adverse effects, complications have been reported even in normal infants [1-3]. A recent publication concluded that the incidence of disseminated BCG infection is one to three cases per million doses $[1,4]$. Though disseminated TB has occasionally been reported following BCG, the latter still remains an effective and safe vaccine. The overall protective value of BCG against disseminated TB is 78\% [4].

\section{References}

1. Bannon MJ. BCG and tuberculosis. Archives Diseases of Childhood 1999; 80: 80-3.

2. Clark JE, Cant AJ. Pitfalls in contact tracing and early diagnosis of childhood tuberculosis. British Medical Journal 1996; 313: 221-2.

3. Desai M, Spencer D. Early diagnosis of childhood tuberculosis. British Medical Journal 1996; 313: 1083-4.

4. Ormerod LP, Palmer C. Tuberculin reactivity after neonatal percutaneous BCG immunisation. Archives Diseases of Childhood 1993; 69: 1551.

\section{A new definition and description of medical professionalism}

\section{Definition}

Medical professionalism signifies a set of values, behaviours and relationships that underpins the trust the public has in doctors.

\section{Description}

Medicine is a vocation in which a doctor's knowledge, clinical skills, and judgment are put in the service of protecting and restoring human well-being. This purpose is realised through a partnership between patient and doctor, one based on mutual respect, individual responsibility, and appropriate accountability.

In their day-to-day practice, doctors are committed to:

- integrity

- compassion

- altruism

- continuous improvement

- excellence

- working in partnership with members of the wider healthcare team.

These values, which underpin the science and practice of medicine, form the basis for a moral contract between the medical profession and society. Each party has a duty to work to strengthen the system of healthcare on which our collective human dignity depends.

The Royal College of Physicians Working Party on Medical Professionalism. [See: Horton R. Medicine: the prosperity of virtue. The Lancet 2005; 366: 1985-7.] 